\title{
ENGINEERING AND ECONOMIC EVALUATION OF THE PRODUCTION OF COPPER NANOPARTICLES USING RONGALITE AS REDUCING AGENT
}

\author{
Nia Purnamaningsih*, Asep Bayu Dani Nandiyanto** \\ * Departement Kimia, Universitas Pendidikan Indonesia \\ ** Departement Kimia, Universitas Pendidikan Indonesia
}

Correspondence Author: nandiyanto@upi.edu

\begin{tabular}{|c|c|}
\hline Info Artikel : & ABSTRACT \\
\hline \multirow[t]{2}{*}{$\begin{array}{l}\text { Sejarah Artikel : } \\
\text { Menerima : } \\
11 \text { Nov } 2019 \\
\text { Revisi : } \\
\text { 05 Des } 2019 \\
\text { Diterima : } \\
13 \text { Jan } 2020 \\
\text { Online : } \\
01 \text { Febr } 2020 \\
\text { Keyword : } \\
\text { Copper Nano } \\
\text { Particles, } \\
\text { Economic } \\
\text { Evaluation, } \\
\text { Reducing Agent, } \\
\text { Chemical } \\
\text { Reduction } \\
\text { Method. }\end{array}$} & $\begin{array}{l}\text { The purpose of this study was to analyze the Economic Evaluation in the } \\
\text { Production of Copper Nanoparticles using Rongalite as Reducing Agent, an } \\
\text { experimental method carried out in the perspective of engineering and } \\
\text { economic evaluation. Technical analysis was performed using simple mass } \\
\text { balance analysis, while economic evaluation was carried out using several } \\
\text { economic parameters, including Payback Period (PBP), Break Even Point } \\
\text { (BEP), and Cummulative Net Present Value (CNPV). To support the analysis, } \\
\text { all data were taken based on the available online shopping webs. All } \\
\text { calculations were carried out in ideal conditions for } 20 \text { years of production. } \\
\text { Economic evaluation is carried out by giving } 5 \text { conditions }(0 ; 20 ; 40 ; 60 ; \text { and } \\
80 \%) \text { to the variable price variations in cost, sales, fixed cost, and labor. } \\
\text { Economic evaluation analysis results showed that price variations can affect } \\
\text { the CNPV curve to Life Time. In the variable cost, fixed cost, and labor } \\
\text { variable price curves, it is found that the condition of } 0 \% \text { is the highest curve } \\
\text { compared to other conditions. In sales price variations, the } 80 \% \text { condition is } \\
\text { the highest curve. In conclusion, all price variation curves show profits. The } \\
\text { benefits of this research are the large-scale economic evaluation data on } \\
\text { copper nanoparticle production. }\end{array}$ \\
\hline & INTISARI \\
\hline $\begin{array}{l}\text { Kata Kunci : } \\
\text { Partikel Nano } \\
\text { Tembaga, } \\
\text { Evaluasi } \\
\text { Ekonomi, } \\
\text { Reduktor, } \\
\text { Metode Reduksi } \\
\text { Kimia }\end{array}$ & 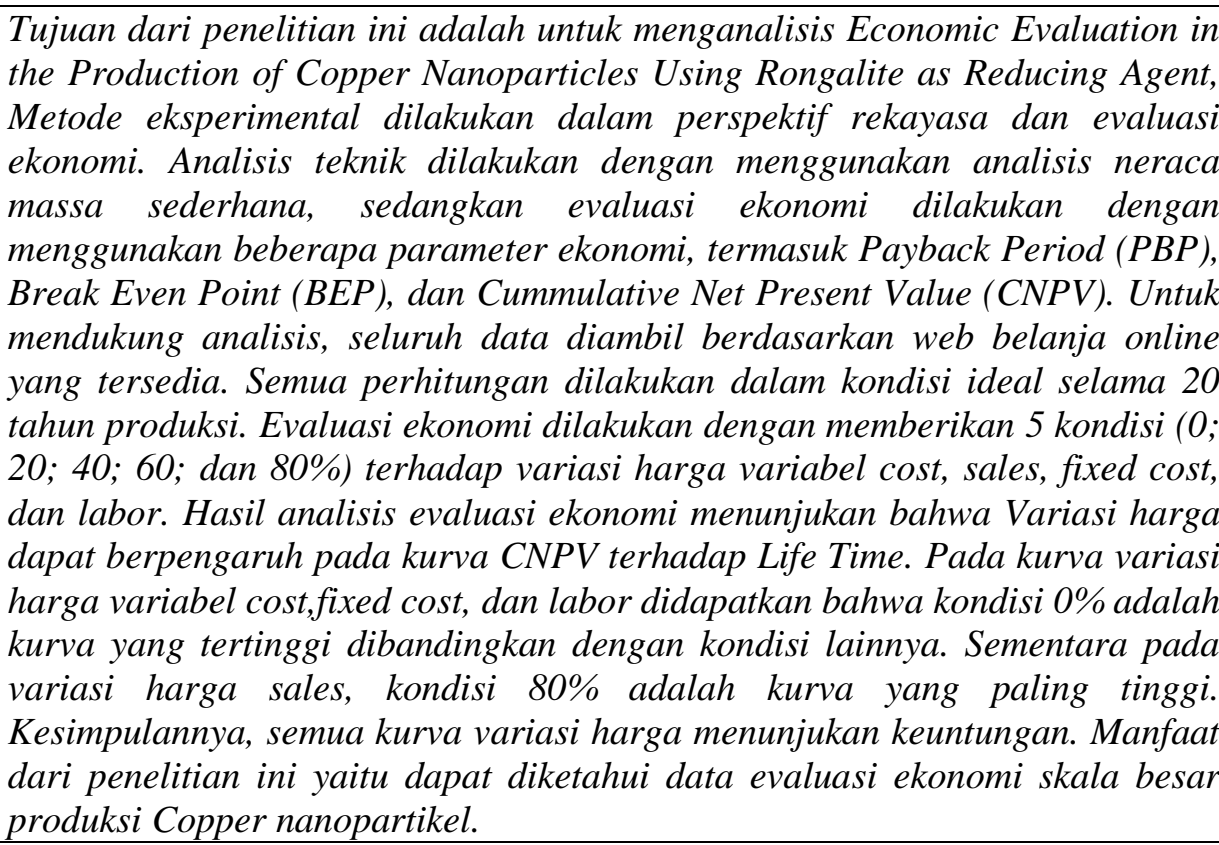 \\
\hline & \\
\hline
\end{tabular}




\section{INTRODUCTION}

Copper nanoparticles $(\mathrm{Cu} N \mathrm{NPs})$ in recent years have come to the attention of researchers because of their attractive chemical and physical properties and low preparation prices. Copper nanoparticles have been widely applied as antimicrobial materials, sensors and catalysts (Kulkarni, Jareb and Kadlagb, 2013).

In some researches (Pita et al, 2017), copper nanoparticles are made through the principle of green chemistry by the reduction method. The volume of bioreductor solution and precursor mixed with a ratio of $1: 1 ; 1: 2 ; 1: 3$; and $1: 4$. The results of copper nanoparticles are greenish brown.

Several methods used for the synthesis of copper nanoparticles are physical and chemical synthesis methods. The disadvantages of both methods are the need for expensive reagents, dangerous reaction conditions (high temperature and pressure), and longer processing times (Lanje et al., 2013). The physical and chemical processes are hydrothermal, electrochemical, sol gel and chemical reduction (Kulkarni, Jareb and Kadlagb, 2013).

Based on these four methods, the synthesis of copper nanoparticles that is widely used is the chemical reduction method. Although chemical reduction is in great demand, the reducing agent used is still a dangerous synthetic reducing agent. $\mathrm{Cu}-\mathrm{NPs}$ were obtained by reducing $\mathrm{CuSO}_{4} .5 \mathrm{H}_{2} \mathrm{O}$ with $\mathrm{NaBH}_{4}$ (Fakhri, Jaleh and Nasrollahzadeh, 2014).

Specifically, we recently studied the electrosynthesis of copper nanoparticles (Cu-NPs) and proposed their use in bioactive nanocomposites deposited on sterile substrates as thin films(Cioffi et al., 2005). Synthesis of Cu-NPs through chemical methods under the surrounding atmosphere, with Cts as stabilizers, hydrazine as a reducing agent and ascorbic acid as an antioxidant (Usman et al., 2012). In this study, rongalite was used as a novel reducing agent to overcome these limitations for synthesis of the Cu-NPs (Patil, Ryu and Kim, 2018).

However, research (Patil, Ryu and Kim, 2018) has not been written about the economic evaluation of copper nanoparticle synthesis on an industrial scale, so to provide that data, we will present economic evaluation data in this report. The results of these studies encourage further research into the synthesis of copper nanoparticles.

The purpose of this study is to analyze economic evaluation data in $\mathrm{Cu}$ NPs production using rongalite as a reducing agent. The evaluation results obtained affect the CNPV / TIC (\%) curve towards Life Time (year) when variations are made. The impact of this research is knowing the large-scale economic evaluation data of $\mathrm{Cu}$ nanoparticle production.

Figure 1 explains the flowchart $\mathrm{Cu}$ NPs from the beginning of the material entering the reactor to become a product.

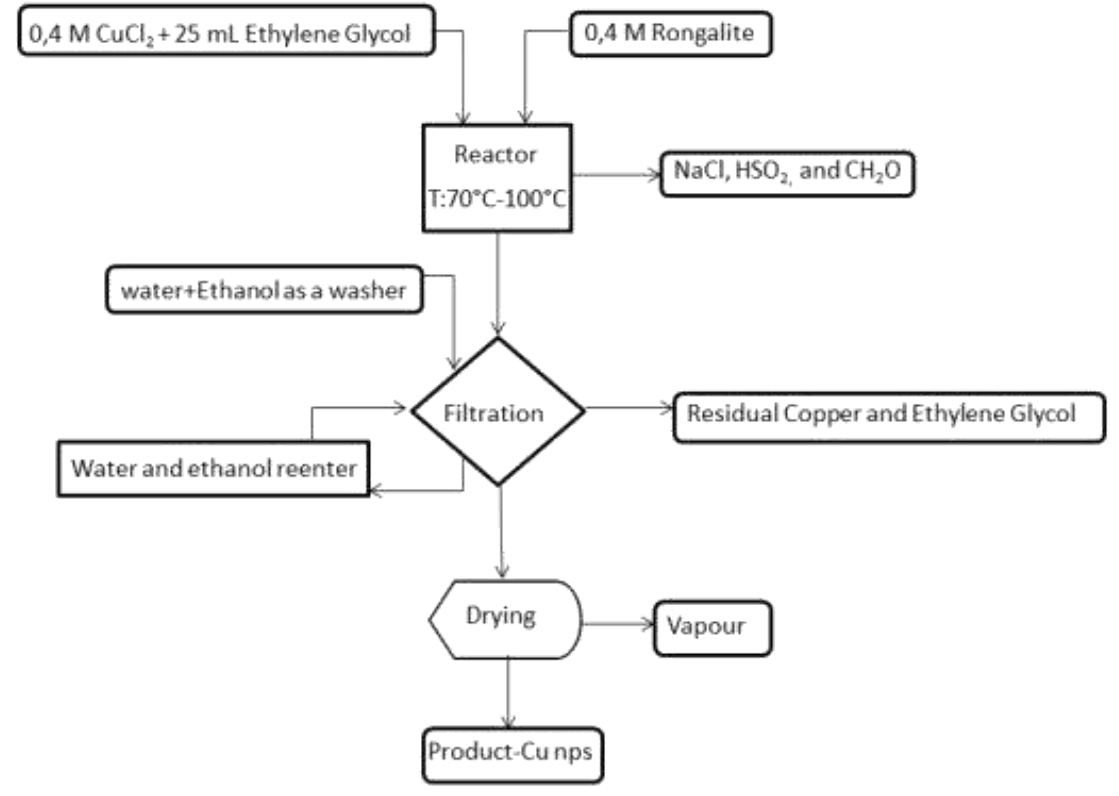

Figure 1. Flow chart of $\mathrm{Cu}$ NPs production. 


\section{RESEARCH METHODOLOGY}

\subsection{Theoretical Synthesis of Cu Nanoparticles}

$\mathrm{Cu}$ NPs can be synthesized using the reduction method. Pati et al has successfully synthesized $\mathrm{Cu}$ NPs from $0.4 \mathrm{M}$ of $\mathrm{CuCl}_{2}$ was dissolved in $25 \mathrm{~mL}$ of ethylene glycol with constant stirring at $70^{\circ} \mathrm{C}$ to $100^{\circ} \mathrm{C}$ for 10 minutes.

Later, 0.4 M rongalite solution was added slowly into a reaction with rapid stirring. Within few minutes, solution color will change to white color. After 5 to 20 minutes, it turns into brown color i.e $\mathrm{Cu}-\mathrm{NPs}$.

After completion of the reaction, synthesized Cu-NPs were washed with water and ethanol two-three times and collected though the centrifuge (Patil, Ryu and Kim, 2018).

The chemical reaction of the $\mathrm{Cu}$ nanoparticle synthesis process is as follows:

2 Rongalite $_{(\mathrm{s})}+\mathrm{CuCl}_{2(\mathrm{aq})} \rightarrow \mathrm{Cu}_{(\mathrm{s})}+2 \mathrm{NaCl}_{(\mathrm{s})}+2 \mathrm{CH}_{2} \mathrm{O}+2 \mathrm{HSO}_{2}$

\subsection{Economic Evaluation}

To determine economic evaluation parameters such as PBP, BEP, and CNPV, data in the form of equipment, raw material and utility prices are needed. In this study, the prices above were obtained from online shopping such as Alibaba.com. All data is used to calculate economic evaluation parameters through simple mathematical equations based on the literature (Nandiyanto, 2018).

- PBP is calculated based on the life time point when CNPV/TIC reaches zero.

- BEP is calculated by comparing the fixed costs against the difference between sales and variable costs.

- CNPV is obtained from NPV values at specific times. CNPV is calculated by adding up the NPV value from the start of the project. NPV is obtained by multiplying cash flow by a discount factor.

To obtain the above values, assumptions are needed to facilitate the calculation of economic evaluation. In this study, the assumptions used are as follows:

- The calculation used is based on conversion 1 USD = 14,213 IDR (Bank Indonesia 2019);

- Price of $\mathrm{CuCl}_{2}$ and rongalite in kg respectively are 62.013 IDR and 72.108 IDR. While the price of aquadest, ethanol $96 \%$, and ethylene glycol in a row per L are 14,000 IDR, 22,500 IDR, 14,421 IDR (Alibaba.com 2019);

- The labor wage is IDR 240,000,000 annually the project employed 4 workers as a labor (Nandiyanto, Maulana et al., 2018);

- The project produces 8 times a day's production;

- The amount of $\mathrm{Cu}$ nanoparticles obtained in one production is $1.5 \mathrm{~kg}$;

- The project operates for 20 years;

- The project runs for 5 working days a week for a total of 240 days a year;

- The utility fee to be paid annually is $122,400,000$ IDR;

- The discount rate is $15 \%$ annually (Nandiyanto, Maulana et al., 2018);

- The income tax is $10 \%$ (Nandiyanto, Maulana et al., 2018);

- Total investment cost (TIC) is calculated based on the Lang Factor;

- Direct-type depreciation is used to calculate the value of depreciation.

- There is a loss of mass of chemical compounds transferred by $5 \%$ of the initial mass in each transfer process

The economic evaluation parameters above will be calculated for the manufacture of $\mathrm{Cu}$ NPs with ethylene glycol and as a washing agent i.e. distilled water and ethanol. Furthermore, the results of these calculations are treated with a number of conditions such as varying the prices of variable costs, sales, fixed costs, and labor to evaluate feasibility.

\section{RESULTS AND DISCUSSION}

\subsection{Engineering Perspective}

A project plant is divided into four areas: the process area, storage, utilities, and services. A process flow diagram for the production (Silla, 2003) of Cu NPs is shown in Figure 2.

ISSN Print $\quad$ : 1979-7141

ISSN Online : 2541-1942 
Figure 2 show the flow of the project from start to finish, there is 1 reactor, 1 filtration reactor and 1 drying machine, from reactor to reactor filtration is connected using a pump to transport the reaction results. The time needed for the production of $\mathrm{Cu}$ nanoparticles is 1 hour. the amount of $\mathrm{Cu}$ NPs produced for one run is $1.5 \mathrm{~kg}$.

Five types of compounds used in this project are solid $\mathrm{CuCl}_{2}$ and rongalite, ethylene glycol, water, and ethanol. The capacity of the reactor can accommodate as much as $500 \mathrm{~L}$ of material in one mixing, the reactor is mixed and reacted between $\mathrm{CuCl}_{2}$ with ethylene glycol and rongalite in a 2: 1 mole ratio. The synthesis process lasted for 30 minutes in the first reactor, the results in the form of $\mathrm{Cu}-\mathrm{NPs}$ and ethylene glycol (Dang et al., 2011).

Then the results of the first reactor are transferred using a pump to the filtration reactor to separate $\mathrm{Cu}$-NPs from ethylene glycol. In the filtration reactor the reaction results are treated using water and ethanol. The filtration reactor process is carried out for 15 minutes, the result of the filtration reactor is $\mathrm{Cu}-\mathrm{NPs}$ and water. $\mathrm{Cu}-\mathrm{NPs}$ is still mixed with the presence of $\mathrm{H}_{2} \mathrm{O}$, so the transfer is done by using human power to avoid pumping to the drying machine. On the drying machine the process lasts for 15 minutes. The purpose of the drying process is to separate water from $\mathrm{Cu}-\mathrm{NPs}$, so that water vapor and pure $\mathrm{Cu}-\mathrm{NPs}$ are produced (Setiyoko, 2018).

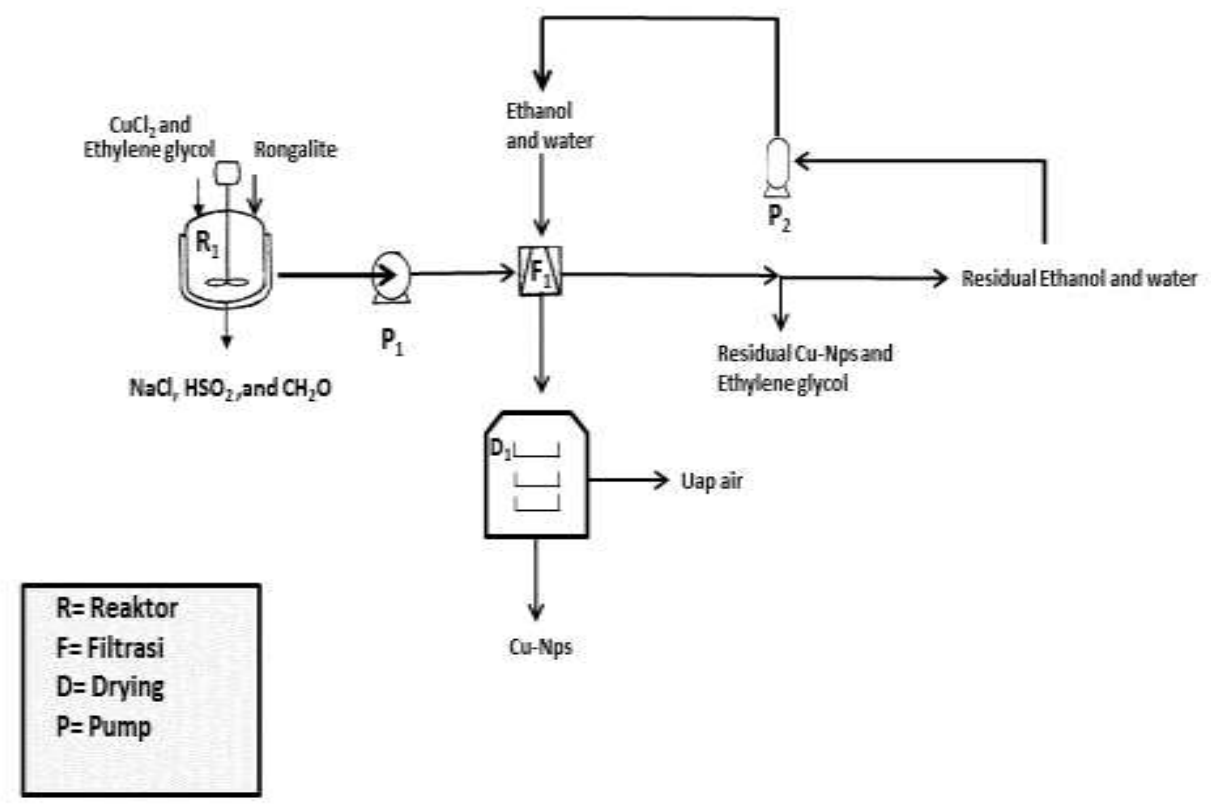

Figure 2. Process flow diagram of $\mathrm{Cu}$ NPs production

Table 1. Several Raw Material Used

\begin{tabular}{|c|c|c|}
\hline $\begin{array}{c}\mathrm{CuCl}_{2} \\
(\mathrm{~kg})\end{array}$ & $\begin{array}{c}\text { Rongalite } \\
(\mathrm{kg})\end{array}$ & $\begin{array}{c}\text { Etilen Glikol } \\
(\mathrm{L})\end{array}$ \\
\hline 1,3445 & 2,36 & 25 \\
\hline
\end{tabular}

\subsection{Economic Evaluation}

\subsubsection{Ideal Condition}

Figure 3 shows the relationship between the CNPV/TIC value on the Y axis and the project life time on the $\mathrm{X}$ axis under ideal conditions for a period of 20 years. In the curve can be found a negative CNPV/TIC (\%) value below $0 \%$ in the first year to the second year, the lowest CNPV/TIC value occurred in the second year which is worth $-130.06 \%$ but after that, the curve goes up again until in the 20th year it reached a value of $2462.32 \%$. 
Figure 3 shows the similarity of the curve with research (Miftahurrahman et al., 2019), namely income in the first 1 to 2 years, also did not benefit. This is because the initial capital costs such as tools needed during production, but after the third year there is a reversal of capital so that what is obtained from the project is that profits continue to increase.

PBP's prediction show the CNPV value every year to see when capital reversal occurs. CNPV value is negative from the first year to the second year ago CNPV returned positive value in the third year with a value of 563,212,000.2 IDR and continued to increase until the 20th year valued at 5,831,809,709 IDR. Thus the production of $\mathrm{Cu}$ nano particles can be considered profitable projects (Nandiyanto et al., 2018).

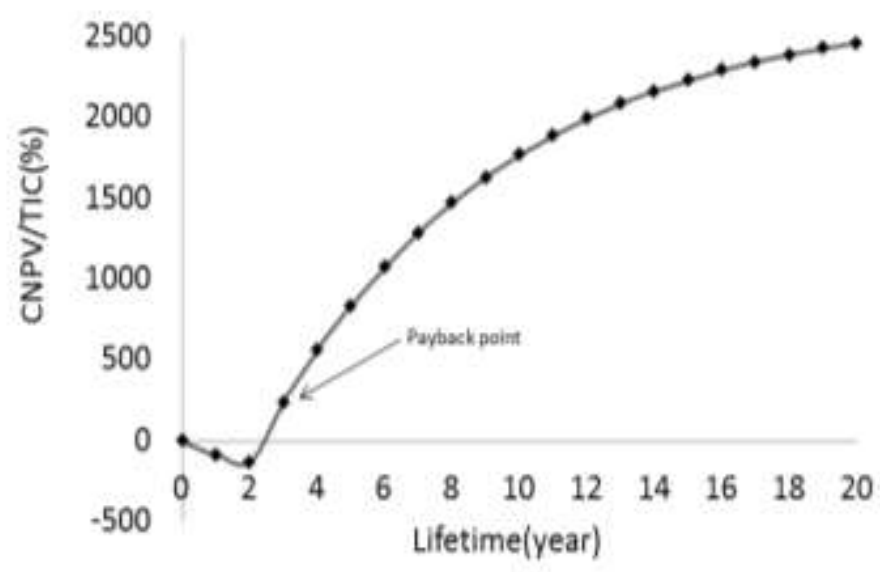

Figure 3. CNPV/TIC Vs Lifetime (year) in Twenty Years of Project in Ideal Condition

\subsubsection{The Effect of Equipment Prices/Fixed Costs}

Figure 4 shows the relationship between the CNPV/TIC (\%) value on the Y axis with the life time (year) on the $\mathrm{X}$ axis at fixed cost (Silla, 2013) prices that vary with 5 percent conditions namely 0 (ideal price), 20, 40,60, and $80 \%$. Fixed cost prices are made to increase gradually every $20 \%$ from 0 to $80 \%$. In the first to second year, there was a decrease in CNPV/TIC in each condition of the fixed price percent price. While in the third to the 20th year the CNPV/TIC value (\%) increased.

The curve of CNPV/TIC (\%) to life time (year) in ideal conditions which also decreased until the second year and increased in the 3rd to the 20th years. The value of CNPV/TIC (\%) continues to decrease in line with the increase in percent fixed cost prices, so that the highest CNPV/TIC (\%) value when fixed cost prices are at 2462,322 or in ideal conditions in the 20th year, and continues to fall to reach a negative value at the fixed cost price with a condition of $80 \%$ at a value of 1311,037 .

Dotted linear graph shows the value of fixed cost prices which has not affected the CNPV/TIC value due to the condition of percent at $0 \%$ so that the curves formed are the same as the CNPV/TIC curve for life time under ideal conditions within a period of 20 years. Box-line curves show the relationship between CNPV/TIC and life time at a condition of $20 \%$ fixed cost. The $20 \%$ curve affects the price of CNPV/TIC so that it looks slightly down in price compared to the point-line curve under ideal conditions. the greater the condition of the percent, the difference in the curve is clearer than the ideal condition. 


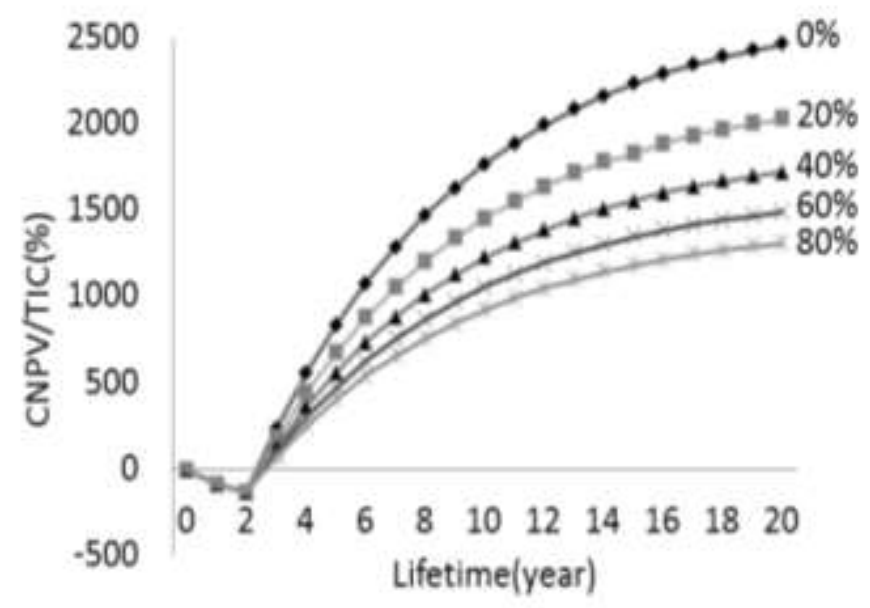

Figure 4. CNPV/TIC Vs Lifetime (year) in Twenty Years of Project under Fixed Cost Variations.

\subsubsection{The Effect of Labor Costs}

Figure 5 shows the relationship between the CNPV/TIC (\%) value and the life time (year) (Silla 2013) labor prices which varies with 5 percent conditions, 0 (ideal price), 20, 40, 60, and $80 \%$. Labor prices are made up gradually every $20 \%$ from 0 to $80 \%$. In the first to second year there was a decrease in CNPV/TIC (\%) in each condition of the percent of labor prices. While in the third to the 20th year the CNPV/TIC value (\%) increased.

The curve of the CNPV/TIC (\%) value and the life time year in ideal conditions which also experienced a CNPV/TIC (\%) decline until the second year and will increase in the 3rd to 20th year. CNPV/TIC (\%) continues to decrease along with the increase in labor price percent, so that the highest CNPV/TIC (\%) value is when labor prices are at 2462,322 or in ideal conditions in the 20 th year, and continues to fall until labor prices reach at $80 \%$ condition, 1897,746.

A point-line linear graph shows the value of labor prices that have not affected the value of $\mathrm{CNPV/TIC}$ due to the condition of percent at $0 \%$ so that the curves formed are the same as the CNPV/TIC curve for life time under ideal conditions within 20 years. The curve at condition is $20 \%$ lower than the CNPV / TIC price under ideal conditions (Nandiyanto et al., 2018). From figure 5 it can be concluded that the higher the percent of labor price conditions, the lower the curve line is formed.

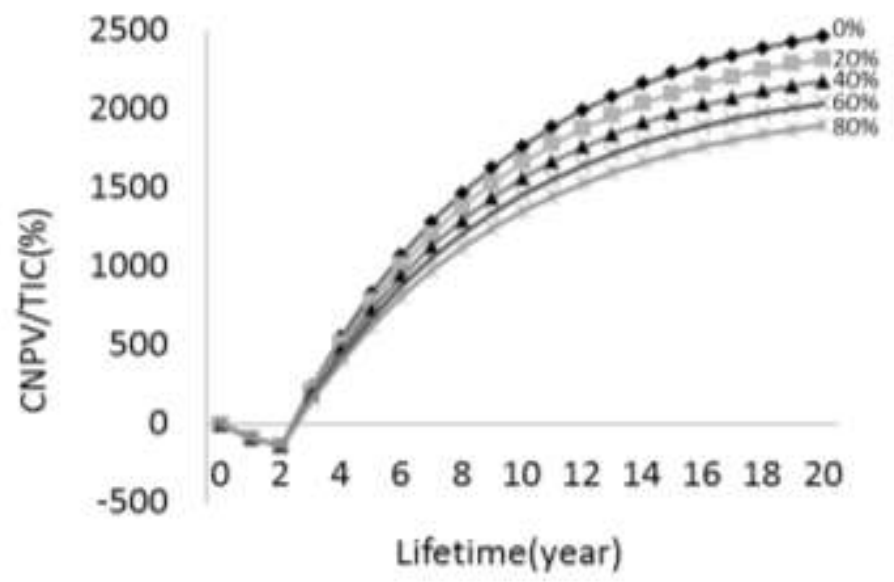

Figure 5. CNPV/TIC Vs Lifetime (year) in Twenty Years of Project under Labor Variations.

\subsubsection{The Effect of Sales Price}

Figure 6 shows the relationship between the CNPV / TIC (\%) value on the Y axis with the life time (year) on the $X$ axis on sales (Nandiyanto 2018) prices that are varied with 5 percent 
conditions, namely 0 (ideal price), 20,40,60, and $80 \%$. Sales prices are made to increase gradually every 20 percent from 0 to $80 \%$. In the first to second year there was a decrease in CNPV / TIC in each condition of the percent of sales prices. While in the third to the 20th year the CNPV/TIC value $(\%)$ increased.

Curve of the CNPV/TIC (\%) value and the life time year in ideal conditions which also experienced a CNPV/TIC (\%) decline until the second year and will increase in the 3rd to 20th year. CNPV/TIC (\%) continues to increase along with the increase in sales price percent, so the highest CNPV/TIC (\%) value is when the sales price is at 7414,194 or at $80 \%$ in the 20th year, and continues to fall until the sales price in ideal conditions are at the value of sales prices 2462,322.

Pointed linear graph shows the value of sales prices that have not affected the value of CNPV/TIC due to the condition of percent at $0 \%$ so that the curves formed are the same as the CNPV/TIC curve for life time under ideal conditions within 20 years. The curve at the condition is $20 \%$ higher than the CNPV / TIC price in ideal condition. From figure 6 it can be concluded that the higher the percentage of sales price conditions, the higher the curve formed compared to the ideal condition.

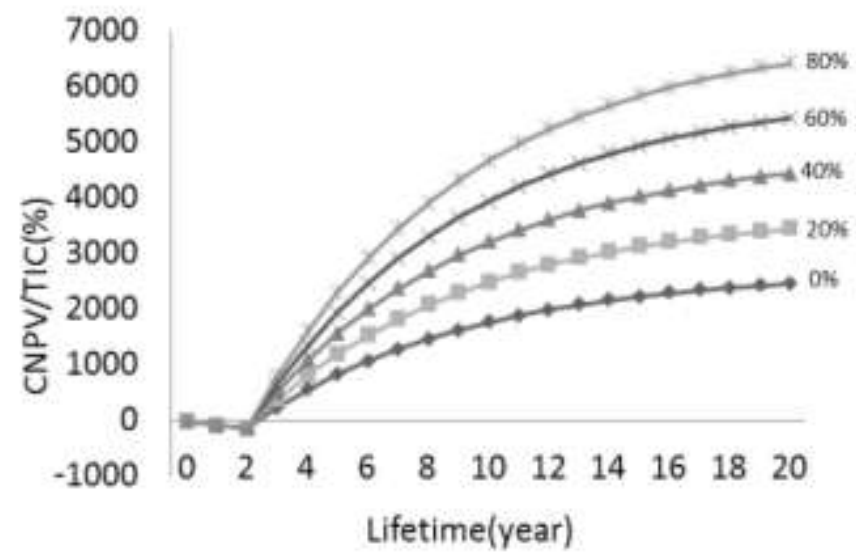

Figure 6. CNPV/TIC Vs Lifetime (year) in Twenty Years of Project under Sales Variations.

\subsubsection{The Effect of Raw Material Prices/Variable Costs}

Figure 7 presents the correlation of CNPV/TIC of the project time under various variable cost price (Nandiyanto, Indrianti et al., 2018). Variable cost is the cost of maintaining the production process at the factory (Shalahuddin, Almekahdinah and Nandiyanto, 2019)..

Variable cost prices are made to increase gradually every 20 percent from 0 to $80 \%$. In the first to second year there was a decrease in CNPV/TIC in each condition percent of the variable cost price. While in the third to the 20th year the CNPV/TIC (\%) value increased.

Curve of the CNPV/TIC (\%) value and the life time year in ideal conditions which also experienced a CNPV/TIC (\%) decline until the second year and will increase in the 3rd to 20th year. CNPV/TIC (\%) continues to decrease along with the increase in the percent price of variable cost, so that the highest CNPV/TIC (\%) value is when the variable cost price is at 7414,194 or at $80 \%$ in the 20th year, and continues to fall until variable cost prices under ideal conditions are at the value of sales prices 2462,322 .

A point line linear graph shows the price value of variable cost that has not affected the $\mathrm{CNPV} / \mathrm{TIC}$ value because the percent condition is at $0 \%$ so that the curves formed are the same as the CNPV/TIC curve for life time under ideal conditions within 20 years. The curve at condition is $20 \%$ lower than the CNPV / TIC price under ideal conditions.

Figure 7 concluded that the higher the condition of the variable cost percent price, the lower the curve formed compared to the ideal condition. In the study (Miftahurrahman et al., 2019) variations in variable costs were also carried out, although the varying costs $(100,50,0,-50$, and $100 \%$ ) were different, the production remained quite profitable. 


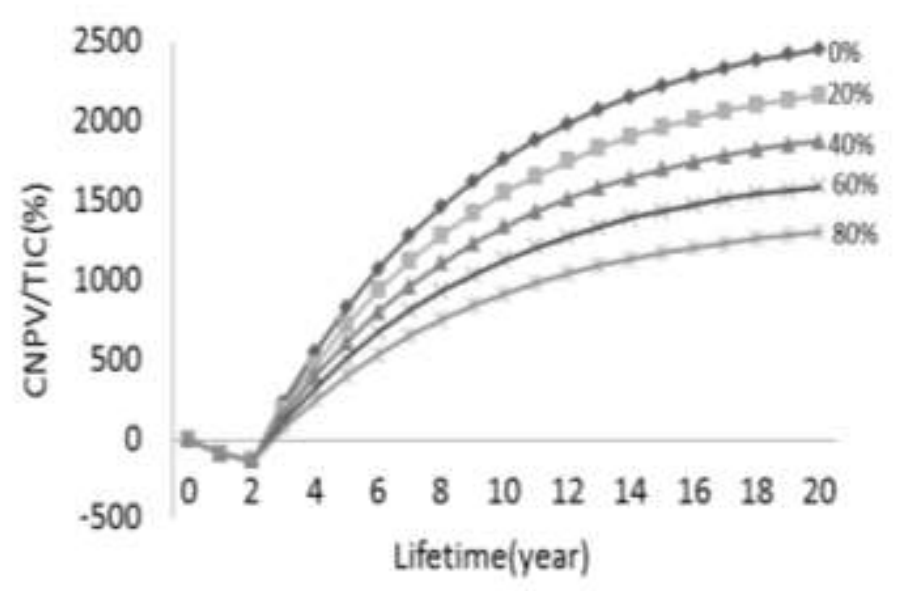

Figure 7. CNPV/TIC Vs Lifetime (year) in Twenty Years of Project under Variable Costs Variations

\section{CONLUSION}

The production of $\mathrm{Cu}$ nanoparticles has been evaluated from economic evaluation studies. An economic evaluation presents the advantages of this project. To increase the quantity of profits, sales prices must be increased. We find that the highest profit is obtained when using $80 \%$ of the sales price. Even though the variable cost, fixed cost, and labor price variation curve found that the condition of $0 \%$ is the highest curve compared to $20,40,60$, and $80 \%$. 


\section{REFERENCE}

Aji Setiyoko, F., 2018, Biosintesis dan Evaluasi Anti Mikroba Nanopartikel Tembaga ( $\mathrm{Cu}$ ) Menggunakan Ekstrak: Institut Pertanian Bogor.

Alibaba.com, 2019, Product Below: Available at: m.alibaba.com/trade/search? (Accessed: 16 September 2019).

Bank Indonesia, 2019, Informasi Kurs. Available at: Bi.go.id/moneter/informasi-kurs/transaksibi/default.aspx (Accessed: 22 October 2019).

Cioffi, N. et al., 2005, Synthesis, analytical characterization and bioactivity of $\mathrm{Ag}$ and $\mathrm{Cu}$ nanoparticles embedded in poly-vinyl-methyl-ketone films: Analytical and Bioanalytical Chemistry, 382(8), pp. 1912-1918.

Dang, T. M. D. et al., 2011, Synthesis and optical properties of copper nanoparticles prepared by a chemical reduction method: Advances in Natural Sciences: Nanoscience and Nanotechnology, 2(1).

Fakhri, P., Jaleh, B. and Nasrollahzadeh, M., 2014, Synthesis and characterization of copper nanoparticles supported on reduced graphene oxide as a highly active and recyclable catalyst for the synthesis of formamides and primary amines: Journal of Molecular Catalysis A: Chemical. Elsevier B.V., 383-384, pp. 17-22.

Kulkarni, P. S., Jareb, K. and Kadlagb, S., 2013, Green synthesis of copper nanoparticles using ocimum sanctum leaf extract: Journal of Karnataka, 3(7), pp. 999-1005.

Lanje, A. S. et al., 2013, Low temperature dielectric studies of zinc oxide ( $\mathrm{ZnO}$ ) nanoparticles prepared by precipitation method: Advanced Powder Technology. The Society of Powder Technology Japan, 24(1), pp. 331-335.

Miftahurrahman, G. et al., 2019, An Economic Evaluation on Scalling-up Production of Nano Gold from Laboratory to Industrial Scale: Indonesian Journal of Computing, Engineering and Design 1(1), pp. 29-36.

Nandiyanto, A. B. D., 2018, Cost analysis and economic evaluation for the fabrication of activated carbon and silica particles from rice straw waste: Journal of Engineering Science and Technology, 13(6), pp. 1523-1539.

Nandiyanto, A. B. D. et al., 2018, Engineering Analysis and Economic Evaluation of the Synthesis of Composite $\mathrm{CuO} / \mathrm{ZnO} / \mathrm{ZrO} 2$ Nanocatalyst: IOP Conference Series: Materials Science and Engineering, 306(1).

Nandiyanto, A. B. D., Indrianti, J., et al., 2018, Economic Analysis of the Conventional Production of Traditional Brem Food: IOP Conference Series: Materials Science and Engineering, 288(1).

Nandiyanto, A. B. D., Maulana, A. C., et al., 2018, Economic Evaluation of the Production Ethanol from Cassava Roots: IOP Conference Series: Materials Science and Engineering, 288(1).

Patil, S. A., Ryu, C. and Kim, H., 2018, Synthesis and Characterization of Copper Nanoparticles ( $\mathrm{Cu}-\mathrm{NPs}$ ) using Rongalite as Reducing Agent and Photonic Sintering of $\mathrm{Cu}-\mathrm{NPs}$ Ink for Printed Electronics: International Journal of Precision Engineering and ManufacturingGreen Technology 5(2), pp. 239-245.

Pita Rengga, W. D., Hapsari, W. P. and Ardianto, D. W., 2017, Sintesis nanopartikel tembaga dari larutan $\mathrm{CuNO} 3$ menggunakan ekstrak cengkeh (Syzygium aromaticum): Jurnal Rekayasa Kimia \& Lingkungan, 12(1), p. 15.

Silla, H., 2003, Chemical Process Engineering Design and Economics., Textbook. New York: Marcel Dekker, Inc.

Shalahuddin, F. A., Almekahdinah, S. S. and Nandiyanto, A. B. D., 2019, Preliminary Economic Study on the Production of ZnO Nanoparticles Using a Sol-Gel Synthesis Method: Jurnal Kimia Terapan Indonesia, 21(1), pp. 1-6.

Usman, M. S. et al., 2012, Copper nanoparticles mediated by chitosan: Synthesis and characterization via chemical methods: Molecules, 17(12), pp. 14928-14936. 